\title{
Noise, screaming and shouting: Classroom acoustics and teachers' perceptions of their voice in a developing country
}

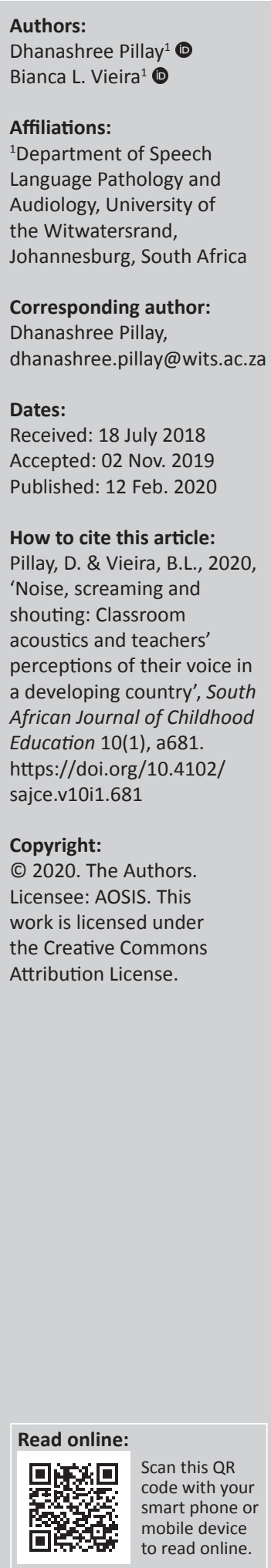

Background: The vocal demand on teachers may predispose them to vocal difficulties. This concern is exacerbated by unfavourable classroom acoustics and a large number of learners in a classroom in developing countries such as South Africa. There is a dearth of classroom acoustic protocols in South Africa, which intensifies the effect of noise on teachers as well as learners.

Aims: The aims of this study were to determine the acoustic properties within the teaching environments and to fix the foundation-phase teachers' perceptions of their voice.

Setting: The study was conducted in Foundation Phase classrooms in South Africa.

Methods: A classroom acoustical screening survey was utilised to conduct classroom observations. A voice handicap questionnaire was used to determine teachers' perceptions.

Results: There were two sample groups: ten schools with 31 foundation-phase classrooms and 31 teachers. Teachers perceived that their voices are affected by occupational demands, with predominantly physical symptoms being reported. Excessive background noise levels were evident in all classrooms. Air traffic noise and noise from adjoining classrooms were the main contributors.

Conclusion: The need for classroom acoustic specifications and design of classrooms are essential as both teachers and learners experience the effects of noise exposure. The implementation of noise reduction in classrooms has the potential to improve the performance of teachers and learners. In a developing country, schools are unique institutions in terms of structure, and therefore additional research is required to determine what building structures may be beneficial for future school buildings. The findings could assist developing countries in the formulation of polices that align with the best practices for acoustically suitable educational settings that benefit both teachers and learners.

Keywords: teachers' voice; classroom acoustics; developing country; teaching and learning; South Africa.

\section{Introduction}

Education is at the forefront of planning and development of any country. In South Africa, the Department of Basic Education (DBE) governs the schooling system. The most recent 2016 statistics of DBE, comprising ordinary ${ }^{1}$ schools and special needs institutions (Early Childhood Development Centres and special schools), published in 2018, reveal that 29749 established public and registered independent education institutions submitted statistical data. The data included 25574 ordinary schools and 4175 education institutions. In 2016, there were 14795 primary schools, with 6929834 learners and 203139 educators. It is predicted that these numbers would escalate by 2020 . According to the 2016 statistics, population density in South Africa accounts for rural provinces having proportionally more schools with fewer learners than the more urbanised provinces.

The Gauteng province is the smallest province in South Africa with the highest number of inhabitants in relation to the other eight provinces. The urban classrooms in Gauteng are therefore significantly more populated than rural classrooms, with $11 \%$ of the total national ordinary schools serving $17.9 \%$ of the country's learners in Gauteng. Overcrowded classrooms are a reality in public schools in Gauteng, thus resulting in increased noise in the teaching and learning environment. In 2016, the highest proportion of learners in ordinary schools was found in the

1.0rdinary schools include public and independent basic education institutions in South Africa, excluding Early Childhood Development (ECD) centres and special schools as per the Education Statistics in South Africa 2016, published in 2018 by Department of Education. 
foundation-phase (33.4\%). The South African basic education sector caters for the foundation-phase from Grade R to Grade 3. Between 2013 and 2016, there was a 3.5\% increase in the number of learners, with a concurrent decrease of educators by $1.5 \%$. This alarming disparate impact of decreasing teacher numbers and increasing learners indicates a negative shift that is inevitably stressing the basic education system.

Improvement in education systems ensures that there is a higher throughput rate at the end of Grade 12; however, the success of basic education requires inputs from and dedication of teachers. Apart from access to stationary, school shoes, clothing and food, a suitable and effective teaching environment is advantageous for learning and teaching. The Department of Basic Education's regulations relating to minimum norms and standards for public school infrastructure as per the Government Gazette No. 37081 (2013) illustrates a lack of details pertaining to the specifications of building materials in relation to acoustic parameters for noise reduction in support of optimal teaching and learning.

The acoustics and noise control within South African schools has been neglected (Van Reenan \& Karusseit 2017) as it is trumped by the areas of greater burden such as the lack of access to education, food, water and sewerage systems in schools. A paradigm shift is necessary to refocus on the mindset that supports teachers and learners to achieve their goals in an education-friendly and barrier-free environment. The acoustics of an educational setting plays a significant role in the teaching and learning outcomes. The South African guidelines relating to the planning for public schools infrastructure (2012) stipulated that a school may not be located close to or adjacent to business centres, railway stations, taxi ranks, public hostels and busy roads, unless adequate preventative measures have been taken to ensure the safety of learners. However, the guidelines do not indicate why these areas have been highlighted. If noise exposure is the rationale for including the aforementioned areas, then the guideline must ensure that a maximum noise limit and preventative measures are set in place to indicate when it may be safe to disregard the guidelines as stipulated in the later part of the clause.

Structures such as ventilation, temperature, room finishes and roofing are focal areas when trying to minimise noise within the learning environment. There is an absence of specific acoustic standards for classroom acoustics in South Africa and the concern was revealed after a study illustrated that the majority of South African schools have background noise levels (BNLs) that exceed the recommended limit of 40 decibels $(\mathrm{dB})$ in an unoccupied room specified by the South African National Standard (SANS) 10103:2004 (Ramma 2007). The recommended noise limit suggested by the American Speech-Language-Hearing Association (2004) is 35 $\mathrm{dB}$ in an unoccupied classroom with a signal-to-noise ratio (SNR) of $+15 \mathrm{~dB}$. A study conducted at two public schools in Tshwane, South Africa, recorded noise levels that exceeded 70 dBA (A-weighted decibels) during the baseline period $32.8 \%$ of the time, exceeded $80 \mathrm{dBA}$ during the baseline $7.5 \%$ of the time and exceeded $90 \mathrm{dBA}$ during the baseline period $0.4 \%$ of the time (Van Tonder et al. 2015).

Classroom communication involves the sharing of information that is unfamiliar and novel, and it is crucial that the acoustics be favourable to optimise learning experiences (Boothroyd 2004). Research evidence supports the hypothesis of increased classroom acoustics within South African schools, which necessitates further research into the communication, teaching and learning within the context of South African education.

Policies and procedures are critical when establishing boundaries and guidelines within the basic education setting. South African policies, standards and regulations that relate to acoustics within a classroom setting were outlined in a review article of 2017 (Van Reenan \& Karusseit 2017). The review article revealed the following:

- The National Policy for an Equitable Provision of an Enabling School Physical Teaching and Learning Environment (DBE 2010): This policy is aimed to define and promote an enabling teaching and learning environment, with the inclusion of the impact of acoustics on learning outcomes. The policy does not provide details on design aspects, although it makes provision for the establishment of norms and standards.

- The DBE published Guidelines Relating to Planning for Public School Infrastructure, 2012: These guidelines recommend a BNL of $40 \mathrm{dBA}-50 \mathrm{dBA}$ and a reverberation time of 0.6 seconds -0.7 seconds. The review article states that it is unclear whether the ambient noise level refers to an occupied or unoccupied classroom noise level, which is a concern. The noise levels in an occupied classroom in South Africa supersede the levels of an unoccupied classroom.

- Department of Basic Education Regulations Relating to Minimum Norms and Standards for Public School Infrastructure, 2013: This policy calls for schools to adhere to principles of inclusive design; however, there is a lack of quantifiable and measurable values regarding the specific design of physical environment.

- The South African National Standards (SANS) 10103 (2008): These state that unoccupied ambient noise level in a classroom is $35 \mathrm{dBA}$, and in 'open space' teaching areas in primary and pre-primary schools, it is to be $45 \mathrm{dBA}$.

- SANS 10400 (2010) National Building Regulations: This document does not provide acoustic requirements for buildings, stating that acoustics only impact comfort or convenience. This can be contested within an educational setting, as poor acoustics negatively impact the transmission of vital information conducive to teaching and learning.

South African standards and regulations pertaining to acoustics and infrastructure of schools provide vague acoustic guidelines (Van Reenan \& Karusseit 2017). Thus, teaching environments have the potential to expose teachers to high noise levels and excessive reverberation, resulting in unnatural vocal use, which could lead to negative effects on voice and the throat. Excessive noise in the environment necessitates 
increase in the intensity of teacher's voice. Consequentially, the change in vocal intensity may negatively impact teacher's personality and may cause physical discomfort and decreased vocal performance because of deviant voice qualities.

Research indicates that strenuous use of one's voice could also lead to tiredness and difficulty during phonation (Hamdan et al. 2007). Speech produced by teachers and learners should not be unintelligible because of noise in the educational setting (Ford 2007), as it may directly affect understanding, processing and academic performance. It is physically harmful for the teacher who often strains his/her voice in an attempt to overcome the noise.

There is paucity of literature on the effects of classroom noise on teacher's perceived vocal health in developing countries with a large number of learners in small classrooms. Research tends to focus on the effect of unfavourable classroom acoustics on a child's performance. Diversity of the South African population could be seen in every facet of the nation, including educational environments. The learners and teachers are as diverse as schools' infrastructure that accommodates them. Formal and informal classrooms are a reality in most developing countries. In spite of the initiatives of empowerment and upward mobility of previously disadvantaged individuals in South Africa, the country has a long road ahead in terms of true equality and the fair distribution of resources. Formal educational infrastructure was designed for one race group during the apartheid era; however, post-apartheid access and education rights highlight the lack of schooling facilities that are available for the South African population. The journey from segregated oppression to apartheid, leading to democracy with freedom has affected the South African educational sector. The progress towards equality continues as decolonisation of the educational system is being tackled at present (Sisk 2017). The apartheid South African government did not foresee the abolition of apartheid; hence, the infrastructure capacity was proportionate to the white race only.

The current democratic SA is marred by the apartheid history as there is a shortage of housing and education facilities; a lock of josbs as well as a struggling public healthcare system.

School infrastructure with poor acoustic properties has harmful consequences for both teachers and learners. However, there is limited documented evidence of classroom acoustics within South African schools, hence the significance of this study. The impact of poor acoustics because of improper infrastructure may lead to vocal stress in teachers who try to compensate for poor acoustics and increased noise in classrooms, thereby impinging on the overall well-being of teachers.

Biopsychosocial models of service delivery in health care encompass all aspects of clients' life in assessment and management phases (Bandura 1999; Henningsen 2015). The principles of integration and inclusion within a biopsychosocial model of care could be applied to teachers and learners in a classroom setting. Noisy teaching environments could result in fatigue, lack of concentration and headaches (Hear-It 2013), which negatively affect teacher's personal well-being. A noisy classroom could negatively affect the academic progress of a learner. Both the teacher and the learner cannot be seen in isolation, as the one needs the other in the teaching and learning ecosystem.

The biopsychosocial aspects considered in this study include vocal impact, social learning and psychological effects of noise on the quality of life of a teacher. There is a need to protect teacher's voice to ensure their longevity in the profession. Hence, this study aimed to describe the acoustic properties within the teaching environments and to determine the foundation-phase teachers' perception of their voice in relation to the acoustic environments in which they teach.

\section{Research methodology Study design}

This study employed a quantitative design to generate data from an acoustical survey (Appendix 1) and to obtain teachers' perception of their voice, which was obtained from close-ended questions on a Likert scale (Appendix 2).

\section{Sampling strategy and study population Sampling strategy}

Permission to contact school principals within the Gauteng, Johannesburg, region was initially obtained from the South African DBE. Thereafter, the school principals and foundationphase heads of departments were purposively contacted to discuss the participation requirements for the study. Public primary schools within the Gauteng province were purposefully selected because of easy access. The acoustic survey was conducted in the foundation-phase classrooms that were conveniently sampled within each school. The teachers in the selected classrooms formed part of the sample.

\section{Study population}

Thirty-one foundation-phase classrooms in 10 public schools were targeted. The acoustic survey was conducted in one classroom in each foundation-phase level.

The teachers in each of the 31 classrooms formed the sample group who completed the questionnaire.

\section{Sample criteria}

Inclusion criteria were as follow:

- The participants needed to be active foundation-phase teachers of Gauteng.

- Both male and female participants could participate.

- A teaching qualification was necessary to validate that individuals were trained teachers.

- A non-smoker because of the negative vocal consequences of smoking.

- No medical condition pertaining to the head or neck region, specifically the vocal structures. 


\section{Data collection and Instrumentation}

The data in this study were collected in the following two phases:

\section{Phase 1: Site surveillance - Classroom Acoustical Survey}

Classroom acoustic properties were measured and documented on the basis of Classroom Acoustical Survey adapted from Johnson and Smaldino (2010). Areas of assessment included the acoustic parameters of the classroom, style of teacher's instructions, seating arrangement and communication access.

\section{Phase 2: Voice Handicap Index Questionnaire}

The Voice Handicap Index (VHI) utilised in this study was developed by Jacobson et al. (1997) and consists of 10 items of three different domains: emotional, physical and functional aspects of voice disorders. Data were collected from the Likert scales measuring response choices that indicated the participant's agreement or disagreement with a statement (Nemoto \& Beglar 2014).

\section{Data analysis}

The data collected in phase 1 of this study were analysed in two categories: teacher's classroom with unfavourable acoustics versus teacher's classroom having optimal classroom acoustics. Once these two categories were separated, their perceptive vocal health was scored and analysed using the VHI and classification system. Data collected were analysed according to a minimal, moderate or significant amount of handicap caused by a possible voice disorder. Descriptive statistics were used to present the data collected in this study.

\section{Ethical considerations}

Ethical clearance was obtained from the Human Research Ethics Committee (HREC Non-medical), University of the Witwatersrand. Permission was obtained from the Department of Education, Gauteng. Confidentiality was afforded to principals and teachers, the names of schools and teachers were replaced with site and participant numbers. Information letters and consent forms provided the participant with the right to withdraw at any time during the research process. If necessary, participants also received a referral to a therapist.

\section{Results and discussion}

Grade R, Grade 1, Grade 2 and Grade 3 classrooms were utilised in this study. Nine of the 10 schools did not have Grade R.

\section{Aim 1: To determine the acoustic properties of teaching environments}

Results were obtained from 31 classrooms. The Classroom Acoustical Survey consisted of an observational section, which included background noise, classroom material and

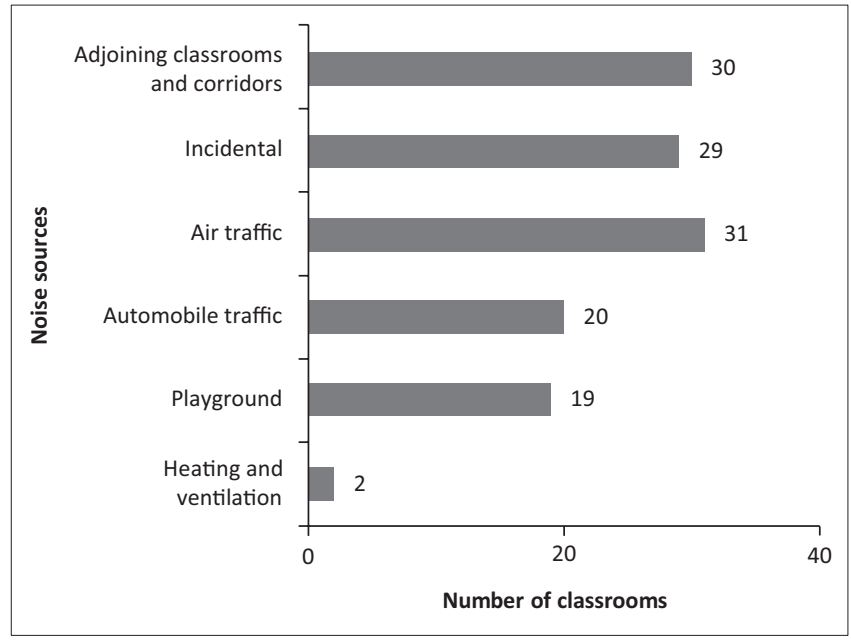

FIGURE 1: Contributors to background noise in all 31 classrooms.

miscellaneous observations. The second section detailed the voice decibel measurements of noise in classrooms.

\section{Section 1: Observational information}

Background noise sources: Figure 1 illustrates the various noise contributors with air traffic noise, noise from adjoining classrooms and incidental sound sources being on the top of the list. All schools were located within a $50 \mathrm{~km}$ parameter of three airports in the Johannesburg region: two international airports and one local airport. Air traffic noise contributed to the background noise in all classrooms. Aircraft noise cannot be instantly manipulated or avoided in a classroom setting. There is a need to interrogate policies that govern air traffic noise and airport proximity to residential communities in South Africa (Pillay, Archary \& Panday 2011). Research conducted in London schools (Shield \& Dockrell 2004) identified road traffic as the principal contributor of noise, and air traffic being evident in 50\% of schools. In South Africa, air traffic has grown exponentially since 1994, and the number of international airline companies flying into South Africa has increased from 12 to 70, with approximately 4 million international passengers flying in and out of South Africa in 2006 (BigIssue 2006). A South African study revealed that school-aged children who reside in the proximity of international airports show early signs of auditory damage (Pillay et al. 2011).

Noise interference from adjacent classrooms and corridors were amongst the most intrusive sound sources after air traffic noises in a study conducted in Hawaii (Berendt, Corliss \& Ojalvo 2000). Incidental sound sources from internal mechanical equipment, children and musical sounds were identified in the current study. School music halls that were proximal to classrooms emitted a recordable noise level that impacted teaching and learning in classrooms. Internal sound sources included intercom interruptions, overhead projector fans and children speaking loudly. Equipment, including motors and fans of computers and projectors, and florescent lights as well as the noise of 
sliding chairs or tables and solid-soled shoes on hard surface floors, contributed to the background noise. The impact of miscellaneous noise sources within a classroom results in communication barriers between teachers and learners. An increase in the loudness of teachers' voice is the resulting compensation strategy.

Material in the classroom: The greatest contributor to reverberation was the height of the ceiling and the absence of acoustical ceiling tiles. All 31 classrooms had ceiling heights that were equal to or higher than $3.35 \mathrm{~m}$. The wall surfaces of classrooms in the current study included plasterboard, concrete, glass and steel. The greater the amount of hard surfaces present in a classroom, the greater would be the reverberation time, because hard surfaces are predominantly sound reflective (Smaldino \& Flexer 2012). Planning of a public school infrastructure must include reverberation factors in relation to the volume of the space and the quality of the surrounding surfaces (Ramma 2007).

Reverberation is calculated in seconds and constitutes the time required for sound pressure to decrease to $60 \mathrm{~dB}$ after the sound source has terminated (Klatte et al. 2010). A combination of noise and reverberation results in speech recognition difficulties in educational settings (Kent 2004), forcing the teacher to increase her/his voice to ensure that the learner is able to hear what is being communicated. The vocal demand increases, hence the risk of vocal damage is high.

Miscellaneous observations: Observations of teacher-tolearner distance in classrooms ranged from $1.5 \mathrm{~m}$ to $6 \mathrm{~m}$. Seating arrangements observed included designs representing clusters, rows and u-shaped or circular seating designs. The most common seating arrangement observed in the foundation-phase classrooms was rows. Three schools had a uniform seating arrangement throughout grade levels, whereas others were arranged based on teacher preference and outcomes. Therefore, various designs and speaker-tolearner distance that were observed could have negative effects on the perception and recognition of speech by learners. There may be increased reverberation because of the distance between the speaker and the learner (Johnson,
Benson \& Seaton 1997) and the direction in which the learner is facing when the teacher is speaking. The classroom seating arrangement may require an increase in the vocal demands of a teacher who must repeat instructions for learners who work in clusters. The vocal demand requires an increase in the frequency of instructions rather than an increase in volume.

\section{Section 2: Decibel measurements}

The teachers' voice level (TVL) was recorded when the teacher was located in her predominant location of instruction. Background noise levels were recorded in occupied classrooms when learners were executing a non-verbal activity.

The softest BNL recorded was $50.4 \mathrm{~dB}$ and the loudest recorded BNL was $70 \mathrm{~dB}$ as depicted in Table 1. The South African guidelines related to the planning of a government school infrastructure state that the extent and quality of absorbing surfaces are to be designed with the objective of providing a general background noise of $40 \mathrm{~dB}-50 \mathrm{~dB}$ (Group 2013). The softest BNLs recorded in all 31 classrooms exceeded this recommended range; hence, all classrooms are not aligned with the optimal level of background noise. The suboptimal surfaces create unfavourable reverberation characteristics that result in classrooms with barriers in teaching and learning.

All 31 classrooms had SNR values below $15 \mathrm{~dB}$; therefore, it is evident that the teachers were required to increase the volume of their voice to overcome the noise in the classrooms. Four classrooms presented with negative SNR values, indicating that the noise in classrooms overpowered teachers' signals. The most unfavourable SNR was $-2.7 \mathrm{~dB}$, which indicates that the noise was $2.7 \mathrm{~dB}$ louder than the teacher's voice in the classroom, thus leading to a break in communication between the teacher and the learner. Although the South African guidelines related to the planning of a government school infrastructure include acoustic guidelines, they do not include voice decibel measurements indicating an optimal SNR (Group 2013); South Africa is therefore dependent on international values in the interim.

TABLE 1: Table illustrating teachers' voice levels, background noise levels and signal-to-noise ratios in each classroom.

\begin{tabular}{|c|c|c|c|c|c|c|c|c|c|c|c|c|}
\hline \multirow[t]{2}{*}{ Schools } & \multicolumn{3}{|c|}{ Grade $\mathbf{R}$} & \multicolumn{3}{|c|}{ Grade 1} & \multicolumn{3}{|c|}{ Grade 2} & \multicolumn{3}{|c|}{ Grade 3} \\
\hline & $\begin{array}{l}\text { TVL } \\
\text { (dB) }\end{array}$ & $\begin{array}{l}\text { BNL } \\
\text { (dB) }\end{array}$ & $\begin{array}{l}\text { SNR } \\
\text { (dB) }\end{array}$ & $\begin{array}{l}\text { TVL } \\
\text { (dB) }\end{array}$ & $\begin{array}{l}\text { BNL } \\
\text { (dB) }\end{array}$ & $\begin{array}{l}\text { SNR } \\
\text { (dB) }\end{array}$ & $\begin{array}{l}\text { TVL } \\
\text { (dB) }\end{array}$ & $\begin{array}{l}\text { BNL } \\
\text { (dB) }\end{array}$ & $\begin{array}{l}\text { SNR } \\
\text { (dB) }\end{array}$ & $\begin{array}{l}\text { TVL } \\
\text { (dB) }\end{array}$ & $\begin{array}{l}\text { BNL } \\
\text { (dB) }\end{array}$ & $\begin{array}{l}\text { SNR } \\
\text { (dB) }\end{array}$ \\
\hline School 1 & - & - & - & 69.4 & 58.2 & 11.2 & 60.3 & 50.4 & 9.9 & 64.3 & 52.0 & 12.3 \\
\hline School 3 & - & - & - & 67.5 & 65.2 & 2.3 & 68.6 & 67.9 & 0.7 & 68.2 & 70.0 & -1.8 \\
\hline School 4 & - & - & - & 61.8 & 54.8 & 7.0 & 65.0 & 54.7 & 10.3 & 67.8 & 53.3 & 14.5 \\
\hline School 5 & - & - & - & 72.7 & 67.6 & 5.1 & 69.6 & 56.6 & 13.0 & 65.6 & 68.3 & -2.7 \\
\hline School 7 & - & - & - & 65.3 & 65.6 & -0.3 & 71.5 & 63.3 & 8.2 & 71.3 & 67.7 & 3.6 \\
\hline School 8 & - & - & - & 70.9 & 60.1 & 10.8 & 71.7 & 63.7 & 8.0 & 75.6 & 64.7 & 10.9 \\
\hline School 9 & - & - & - & 65.1 & 57.8 & 7.3 & 70.3 & 63.3 & 7.0 & 69.7 & 59.5 & 10.2 \\
\hline School 10 & 70.6 & 61.3 & 9.3 & 62.4 & 56.2 & 6.2 & 63.6 & 60.4 & 3.2 & 70.4 & 63.5 & 6.9 \\
\hline
\end{tabular}

BNL, background noise level; SNR, signal-to-noise ratios; TVL, teachers' voice levels; dB, decibels. 


\section{Aim 2: To determine teachers' perception of their voice in terms of three domains, namely, physical, functional and emotional}

The years of teaching experience ranged from 1 to 35 years.

\section{Physical subscale}

Fifty-one per cent of the teachers perceived that their vocal status was affected on the physical subscale. An example of a physical subscale question is: 'my voice sounds creaky and dry'. Scoring more frequently on the physical subscale indicates that these teachers perceived that the vocal strain had a negative effect on their vocal function or output, causing the laryngeal discomfort.

\section{Functional subscale}

The functional subscale was scored as the second highest subscale. An example of a functional subscale question is: 'my voice restricts my personal life and social life'.

Twenty-three per cent of the teachers deemed both physical and functional subscales as being equally affected, which indicated that both vocal function and impact of diminished function were affected equally.

\section{Emotional subscale}

The least scored subscale was the emotional subscale. An example of an emotional subscale question is: 'I feel annoyed when people ask me to repeat myself'.

The emotional subscale included the impact of teachers' response on their vocal status, and the results indicated that minimal emotional impact was perceived by teachers.

Results revealed that teachers within foundation-phase classrooms perceived a negative vocal demand during the teaching and learning process because of excessive noise in classrooms. The lack of classroom infrastructure guidelines in South Africa results in classrooms being built with varying acoustic properties. Teachers experienced challenges in their voices as a result of poor acoustic properties in classroom. Teachers in the current study identified physical and emotional subscales with the highest impact, thus indicating that the consequences of poor vocal use may affect the social aspects of their lives. Poor vocal use in classrooms is likely to have long-term negative effects on teachers' health.

\section{Conclusion}

Hearing is the primary sense needed in mainstream educational settings as children need to listen constantly and continuously in order to optimise their potential (Sornson 2001). Adverse listening conditions place the auditory system and the processing under considerable stress. Research has focussed on the effect of noise on learners; however, the current study looked at the classroom settings with the focus directed on teachers. Background noise in a classroom varies incredibly and has various emanating sound sources as seen in the current study. The predominant sound sources contributing to potentially excessive BNLs are identified to be air traffic noise, noise from adjoining classrooms and incidental sound sources. It is therefore evident that background noise has diverse and multifaceted implications on teachers. This study has found that all 31 classrooms were exposed to various yet similar sound sources and poor SNR measurements. Hard surfaces, high ceilings and extremely reverberant surfaces on walls and floors contributed to poor acoustics in all 31 classrooms studied in this research. The impact of sound sources resulted in an increase in the volume of teacher's voice during teaching and learning activities.

The present study reveals that teachers' have a diminished perception of their vocal function, as a large percentage of them have experienced negative physical symptoms. The South African classroom infrastructure guidelines are ambiguous and therefore there are various interpretations of classroom acoustics. The research results obtained from the current study indicate a need for stricter and more detailed guidelines pertaining to the acoustics and infrastructure in classrooms. Public schools may have financial budgets that cannot include classroom acoustical refurbishment; however, practical strategies are available to improve classroom acoustics in an inexpensive way. Town planning policies have to include detailed acoustic specifications and positioning details for the zoning and building of new public and private school buildings.

The current study was limited to the geographical area of Johannesburg; therefore, future studies must include more regions. The study focussed on the foundation-phase in primary schools; however, a larger study could be conducted to include all grades of primary schools.

In spite of the limitations, this study has valuable data to indicate that vocal training and vocal hygiene strategies must be provided to teachers as a preventative measure because of prolonged vocal use in the presence of unfavourable environmental factors. Although vocal training may not be accessible and affordable in all contexts, teachers must be informed of vocal hygiene tips and medical services for vocal matters.

\section{Acknowledgements}

The authors acknowledge the school principals and teachers for participating in the study.

\section{Competing interests}

The authors have declared that no competing interests exist.

\section{Authors' contributions}

The article was written by D.P., who was the supervisor of the study. B.L.V. was the student researcher of this study. 


\section{Funding information}

This research received no specific grant from any funding agency in the public, commercial, or not-for-profit sectors.

\section{Data availability statement}

The data is available upon request however no further analysis or reporting of data is permitted.

\section{Disclaimer}

The views and opinions expressed in this article are those of the authors and do not necessarily reflect the official policy or position of any affiliated agency of the authors.

\section{References}

American Speech-Language-Hearing Association Working Group on Classroom Acoustics, 2004, Guidelines for addressing acoustics in educational settings, viewed January 2020, from https://www.asha.org/uploadedFiles/elearning/ jss/6173/6173Article4.pdf.

Bandura, A., 1999, 'Social cognitive theory: An agentic perspective', Asian Journal of Social Psychology 2(1), 21-41. https://doi.org/10.1111/1467-839X.00024

Berendt, R.D., Corliss, E.L. \& Ojalvo, M., 2000, Quieting: A practical guide to noise control, University Press of the Pacific, The Minerva Group, Inc.

Biglssue, 2006, The Big Issue, Big Issue, Cape Town.

Boothroyd, A., 2004, 'Room acoustics and speech perception', Seminars in Hearing 25(2), 155-166. https://doi.org/10.1055/s-2004-828666

Department of Basic Education (DBE), 2010, National policy for an equitable provision of an enabling school physical teaching and learning environment, Government Gazette, No. 33283.

Department of Basic Education (DBE), 2018, The 2016 statistics of Department of Basic Education, viewed August 2019, from https://www.education.gov.za/ Portals/0/Documents/Publications/Education \%20Statistic\%20SA\%202016. pdf?ver=2018-11-01-095102-947

Ford, A., 2007, Designing the sustainable school, Images Publishing, New York.
Group, O.B., 2013, The report: South Africa 2013, Oxford Business Group.

Hamdan, A.-L., Sibai, A.M., Srour, Z.M., Sabra, O.A. \& Deeb, R.A., 2007, 'Voice disorders in teachers. The role of family physicians', Saudi Medical Journal 28(3), 422-428.

Hear-It., 2013, Noise affects teachers well-being and health, viewed January 2020, from https://www.hear-it.org/noise-affects-teachers-well-being-and-health.

Henningsen, P., 2015, 'Still modern? Developing the biopsychosocial model for the 21st century', Journal of Psychosomatic Research 79(5), 362-363. https://doi. org/10.1016/j.jpsychores.2015.09.003

Jacobson, B.H., Johnson, A., Grywalski, C., Silbergleit, A., Jacobson, G., Benninger, M.S. et al., 1997, 'The voice handicap index (VHI): Development and validation', American Journal of Speech-Language Pathology 6(3), 66-70. https://doi. org/10.1044/1058-0360.0603.66

Johnson, C.D.C., Benson, P.V. \& Seaton, J.B., 1997, Educational audiology handbook, Singular Publishing Group, San Diego, CA.

Johnson, C.D. \& Smaldino J., 2010, Classroom Acoustical Survey, viewed January 2020, from https://www.nhdeafed.org/wp-content/uploads/2016/09/ANSI.pdf.

Kent, R.D., 2004, The MIT encyclopedia of communication disorders, MIT Press, Cambridge, MA

Klatte, M., Hellbrück, J., Seidel, J. \& Leistner, P., 2010, 'Effects of classroom acoustics on performanceand well-being in elementaryschool children:A field study', Environmen and Behavior 42(5), 659-692. https://doi.org/10.1177/0013916509336813

Nemoto, T. \& Beglar, D., 2014, Likert-scale questionnaires, JALT, Tokyo.

Pillay, D., Archary, K. \& Panday, S., 2011, 'A preliminary study of the effects of aircraft noise on families who reside in close proximity to an airport', South African Family Practice 53(4), 361-365. https://doi.org/10.1080/20786204.2011.10874115

Ramma, L., 2007, 'Rethinking our classrooms: Assessment of background noise levels and reverberation in schools', Education as Change 11(2), 115-130. https://doi. org/10.1080/16823200709487169

Shield, B. \& Dockrell, J.E., 2004, 'External and internal noise surveys of London primary schools', The Journal of the Acoustical Society of America 115(2), 730-738. https://doi.org/10.1121/1.1635837

Sisk, T., 2017, Democratization in South Africa: The elusive social contract, Princeton University Press, NJ.

Smaldino, J.J. \& Flexer, C., 2012, Handbook of acoustic accessibility: Best practices for listening, learning, and literacy in the classroom, Thieme, New York.

Sornson, R., 2001, Preventing early learning failure, Association for Supervision and Curriculum Development, Alexandria, VA.

Van Reenen, C. \& Karusseit, C., 2017, 'Classroom acoustics as a consideration for inclusive education in South Africa', South African Journal of Communication Disorders 64(1), 1-10.

Van Tonder, J., Woite, N., Strydom, S., Swanepoel, D.W. \& Mahomed, F., 2015, 'Effect of visual feedback on classroom noise level', South African Journal of Childhood Education 5(3), 1-6. 


\section{Appendix 1: Classroom Acoustical Survey}

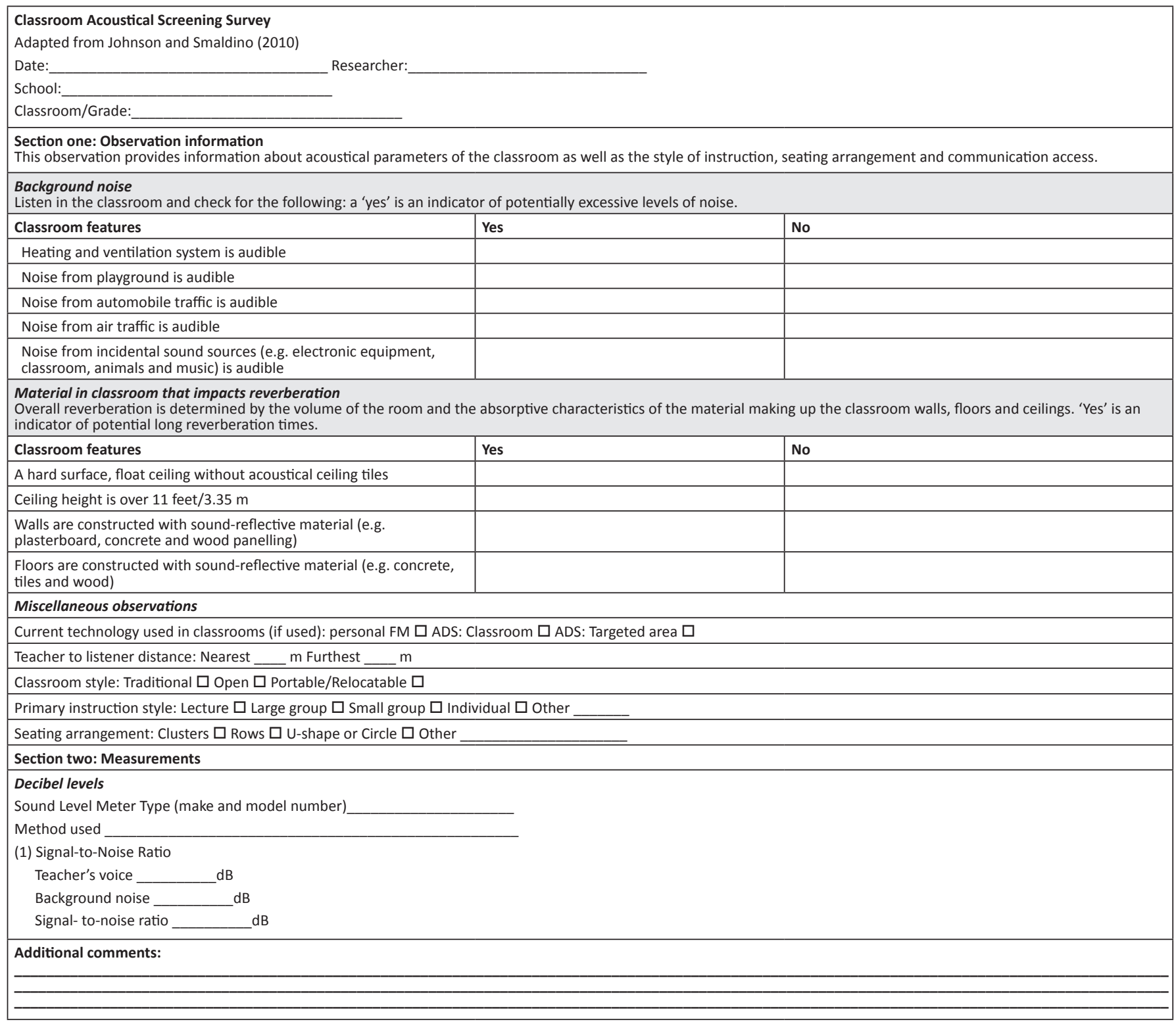




\section{Appendix 2: Voice Handicap Index Questionnaire}

In order to adhere to the sample inclusion criteria established for this research study, please make sure you fit the criteria before completing this questionnaire. Please tick each box if the statement provided is true.

1. I teach in a government school within the Johannesburg area

2. I am a foundation-phase teacher (Grade R, 1, 2 or 3) $\square$

3. I am 22 years of age or older

4. I am a non-smoker

5. I have no medical condition pertaining to the neck or throat region (e.g. throat cancer) $\square$

6. If you have ticked each box (numbers 1-5), you therefore fit the criteria meant for this specific study. Please proceed to fill in the Voice Handicap Index

\section{Voice Handicap Index}

School Name: Date:

Classroom grades: Grade R $\square$ Grade $1 \square$ Grade $2 \square$ Grade $3 \square$

Number of years of teaching experience:

Instructions: These are statements that many people have used to describe their voices and the effects of their voices on their lives. Check the response that indicates how frequently you have the same experience.

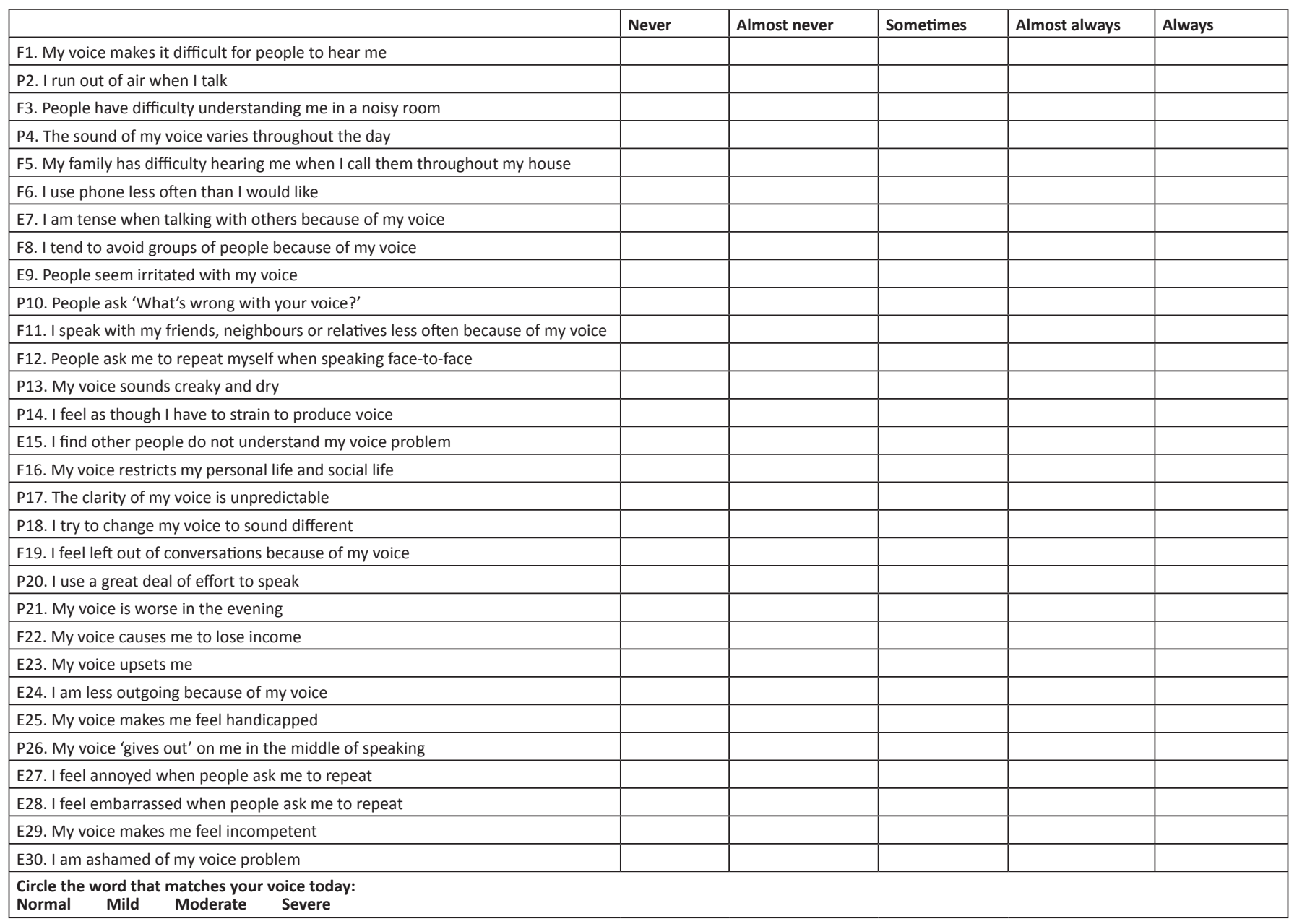

Thank you for your time in completing this questionnaire. Your time and patience are greatly appreciated as your contribution has a great value to the improvement of educational audiology in the classrooms of South Africa. 